\title{
Emotional Intelligence Skills and Self-efficacy Levels: Physical Education Teachers' Perspective
}

\begin{abstract}
Fatima Eid Zaid AL-Adwan
University of Jordan, Faculty of Educational Science, Counseling and Special Needs Section

Majed Mohammad Al - Khayat

Associate Professor, Al-Balqa Applied University, Faculty of Business

doi: 10.19044/esj.2016.v12n10p171 URL:http://dx.doi.org/10.19044/esj.2016.v12n10p171

Abstract

The aim of this study is to investigate the relationship between emotional intelligence skills and self-efficacy levels among physical education teachers from the teachers' own perspective. The researchers developed two scales that measure the emotional intelligence skills; and another one to measure self-efficacy levels for physical education teachers. These two scales were applied on (70) teachers from public and private schools of the Salt Directorate of Education in Jordan. The results show a strong relationship between the emotional intelligence skills and self-efficacy levels among physical education teachers. Therefore, the results also showed that the physical education teachers have high levels of emotional intelligence skills and self-efficacy levels. Also, the results show the presence of statistically significant differences between teachers in the emotional intelligence skills for the benefit of male teachers, and between public and private schools for public schools. The researchers have recommended that it is necessary to teach some training programs about emotional intelligence to physical education teachers in both public and private schools and universities.
\end{abstract}

Keywords: Emotional Intelligence, Self-Efficacy, Physical Education Teachers

\section{Introduction and Background}

Consequently, there has been an outbreak of uncontrolled sensual emotions, where no one is safe from dangers. The unhealthy emotional expression has accelerated and is now considered to be very dangerous. Anger waves usually lead to crimes; depression leads to suicide; and some grieve cases might result to psychological problems (Hubble, 2015). 
Aristotle stated: it's rather easy to get mad at someone, but it's a hard thing to be mad at the right person, at the right time, and in the right place for the right reasons. Technological progress has contributed to solving and explaining many conflicts of the brain and its physiological compositions such as emotions, anxieties, love, and hate. Emotional quotient explained why people with high intelligence may fail in life, and why people with low intelligence could be successful.

Evaluating the person according to his/her intelligence while ignoring the emotional side is considered to be a mistake. Therefore, these emotions assist the brain to find new ideas and solutions to problems (Hakkak et al., 2015). For example, once the person feels hungry, the brain starts to think on how to get food. Its influence also affects the physiological side by increasing the blood flow in cases of anxiety. In addition, it also increases the heartbeats due to fear. Emotional intelligence has its basics, although it was discovered in the early nineties. It requires a significant interest from researchers due to the revolution in the world to solve the problems people are facing and their influences (Pfeiffer, 2001).

The concept of emotional intelligence has great interest because of its efficiency in adapting people's abilities to the needs of life. It has also been widely used in modern articles and researches. Brackett et al. (2011) and Bar-On (2006) pointed the importance of emotional intelligence skills for a person to live a successful social and scholar life in contrast with intellectual intelligence.

The ability of the physical teacher to adapt with his students depends mainly on the recruitment of his mental and emotional abilities. Therefore, the successful teaching process in this case is dependent on the teacher's selfefficacy. It also depends on his emotional experiences and knowledge to fully understand students' actions and emotions. In his study, Alexandre (2013) explained the relationship between the emotional intelligence of the physical teachers and their self-efficacy. Thus, this is because students have different athletic abilities in such a way that the teachers should be able to deal with these problems and find proper solutions. Furthermore, Abdovahabi (2012) approved the positive relationship between the emotional intelligence of the physical teachers and their self-efficacy. The success of the teaching process depends on the skills that the teacher has. Also, Ahadi (2009) discussed the previous relationship. Thus, his study showed that a fulfilled skilled emotional intelligent teacher is the one capable of presenting efficient behavioral scholar duties. Also, he emphasized the importance of training the teachers who lack emotional intelligence skills. Therefore, these skills affect the degree of interaction between them and their students. Moafian \& Ghanizadeh (2009) stated that for physical teachers to be able to solve problems, they should have emotional intelligence skills. Kaufhold \& 
Johnson (2005) also stated the importance of developing emotional intelligence skills for physical teachers. As such, they would encourage their students to solve their own problems more efficiently. Based on the lack of Arabic studies concerning emotional intelligence skills for physical teachers, this study is important in identifying emotional intelligence skills and their relationship with self -efficacy from the teachers' perspective.

Psychologists often use the term intelligence to point out the person's ability to perform intellectual processes. Also, intelligence refers to intellectual abilities such as correlating concepts, the ability to judge, conclude, abstract thinking, and solve problems. Emotional intelligence also contains emotions, moods, and the evaluation of feelings and senses (Gayathri \& Meenakshi, 2013). Goleman (1995) pointed that each brain has two dimensions: the reasonable side that deals with the relationship between things, and the emotional side that deals with emotions. Although these sides are contrary, the stronger side overtakes the person's personality.

Consequently, humanitarian sciences and natural sciences vary in its identification of intelligence. Thus, this is dependent on the researcher's point of view. Thorndike approached one of the emotional intelligence's dimensions known as social intelligence. It was identified as the ability to convince others and let them obey you whether or not they approve of it. In 1960, a book was released that made a big fuss about the intelligence tests. Furthermore, it discussed the concept of social intelligence and how useless it was (Goleman, 1995). Until Gardner changed the traditional concepts of intelligence and developed a multi intelligence theory, he had a main role in the rise of emotional intelligence. Therefore, his model contains two types of intelligence which are intrapersonal and interpersonal (Freedman, 2015).

In 1988, Revein Baron attempted the first trial to measure emotional intelligence. However, he was the first person to use the concept of emotional intelligence coefficient (EQ) (Cherniss \& Goleman, 2006). Then, a new version of emotional intelligence meter was evolved which is dependent on our efficient understanding of ourselves and others (Bar-on, 1997). In 2006, he divided emotional intelligence into five main components and fifteen sub-components (Bar-On, 2006). Consequently, Salovey and Mayar have published an article about emotional intelligence and have identified it in few ways. Emotional intelligence is composed of particular fields such as knowing his/her own emotions, realizing feelings, and having self-motivation. Also, emotional intelligence is the person's ability to positively deal with his/her emotions as well as that of others (Zeidner et al., 2009). They should know the emotions and feelings of the staff and individuals studying in these centers. In addition, they should be aware of their own feelings and emotions and try to control them in order to achieve the organizational goals at the highest speed and with the best quality 
(Hooshmand, 2007). Emotional intelligence is a broad concept involving a wide range of individual skills and abilities. Therefore, it usually refers to interpersonal and intrapersonal skills that are beyond a specific area of previous knowledge of IQ, technical, or professional skills (Khanmohamadi, 2008). Emotional intelligence has been used by many scientists. Rahnavard (2008) stated: "emotional intelligence is the person's ability to deal with his/her feelings to achieve happiness for him and others."

Fisher \& Ashkanasy (2000) identified it as "the ability to control affections, impulsions, and flexibility while dealing with others." Therefore, we can conclude on the following:

- Emotions are the motivators and forces behind a person's attitude.

- Emotional intelligence can be developed and promoted.

- Emotional intelligence includes skills as self-distrainment and the understanding of others.

- Righteous values should be planted in our children.

Emotional intelligence is a developing field that should be taken care of. Therefore, the understanding of emotional and intellectual intelligence depends on the comprehension of the human brain. Consequently, Johnson (2008) came up with four dimensions concerning emotional intelligence:

1- Perceiving Emotions: This is concerning the person's ability to distinguish accuracy from inaccuracy, and truly express these emotions.

2- Using Emotions: It is the ability to properly use emotions, as well as using them in other intellectual processes.

3- Understanding and Analyzing Emotions: It is the ability to categorize emotions into complex emotions such as loving and hating someone at the same time, and the ability to understand the meaning behind these emotions.

4- Managing Emotions: It represents the ability to recognize selfemotions as well as others' and depress negative feelings while expressing positive ones.

Therefore, every person has unique emotional intelligence skills that form the base for psychological adaptation as well as in controlling stress and negative feelings. It also considered the main factor in his/her success, especially in modern science and technology environment. Many situations proved that people with high emotional intelligence rates were able to fully identify their feelings and manage to deal with the feelings of others. Thus, these people are found to be more successful in their lives and more selfcontent. In addition, those with low rates of emotional intelligence usually go through psychological fight that destroys their concentration in life and prevent them from clear thinking. Therefore, it is one of the most important concepts that integrate various cognitive and non-cognitive aspects such as 
thinking and emotion which has been discussed in recent years. Furthermore, it is used in contrast to cognitive intelligence (Nowzari, 2015).

Emotional intelligence is considered a main factor to overcome some psychological crisis. Therefore, many studies have shown a relationship between emotional intelligence and self-efficacy and the value of life (Alexandre, 2013). Other studies have showed a negative relationship between emotional intelligence and behavioral perplexities. Due to the fact that many researchers have developed training programs to develop emotional intelligence skills, the results of those studies were very effective in decreasing the intensity of the behavioral perplexities, improving life quality, and increasing the efficacy of physical education teachers to be more collaborative with their students (Mathews et al., 2004). Haque \& Sanaker (2013) stated that it is important to study emotional intelligence. Hence, it is considered one of the most important topics in psychological science. This is based on the fact that emotions affect people's behaviors and their functions in their daily life.

The physical education teacher is considered to be a major member in the educational process especially for students who are interested in physical activities. Physical education has many goals in both the social and educational life of students. In addition, physical education teacher is a positive role model to his students because they imitate his moves and skills (Nodding, 2002). Therefore, physical education teachers are obligated to be trained and are qualified to be able to manage the classroom and reach their goals. These goals includes the healthy growth of emotional and physical sides of the students. The teacher should not concentrate on the intellectual side and neglect their emotional side. Thus, this may result in the loss of many information. Also, it might allow fear to prevent students from performing mental processes and feel insecure (Zeidner et al., 2009).

The physical education teacher's performance and interaction with his/her students requires self- restraining and control over his/her feelings (Hafezi et al., 2011). The teacher should not be under any psychological stress that could affect his/her performance and interaction with students (Ladan et al., 2010). Therefore, the teacher with high emotional intelligence skills is the least teacher to deal with psychological stress. This is because this requires him/her to form positive relationship with the students by carefully dealing with their emotions and controlling his/her own reactions. Consequently, it also entails managing and understanding the students' feelings and sympathizing with them. Emotional health is really important in having an effective teaching process (Goleman, 2001).

The importance of the physical education teacher and the students' love for his/her class imposes them to have special personal characteristics. Thus, this is the purpose of this study. Also, this is because emotional 
intelligence is an important prerequisite for the success of the educational process. Many studies have proven a relationship between emotional intelligence and the self-efficacy of the physical education teachers (Abdolvahabi et al., 2012).

The concept of self-efficacy first started from the social intellectual theory by Bandura. This states that the person's beliefs towards his/her own abilities have a great influence on his/her choices, problem solving, and persistence in overcoming obstacles. It can also reduce exhaustion and depression that might face him/her while solving many problems (Hoffman, 2013). Furthermore, the person will become more self-efficient and optimistic. He will also be able to achieve his/her goals without getting into unexpected problems. This is because self-efficacy is identified as the person's beliefs about his/her abilities and performance which could affect his/her practical life (Iroegbu, 2015). Consequently, self-efficacy can be developed by four sources:

- Excellent Experience: It is about achieving a task. Also, it is considered to be the most effective means of attaining self-efficacy.

- Observing the Performances of Others: This entails the careful observation of the performances of others. It considers others as role models while trying to solve problems.

-Social or Verbal Persuasion: It involves getting encouragement from others. This helps in promoting self-efficacy. This is because people tend to discuss the steps that led them to achieve a task more than the task itself.

- Psychological State: This involves the person's feeling of achievement, which is called physical arousal. Furthermore, it is related to happiness and physical relief after accomplishing something (Bandura, 1999).

When physical education teacher posses self-efficacy levels, he/she would be more creative and experienced. Emotional intelligence and selfefficacy are related. Therefore, this was proven by many studies (Samuel, 2007). The teacher should be emotionally intelligent and self efficient to achieve his/her educational tasks. Darvish et al. (2011) confirmed that having high rates of self-efficacy could mean that the teacher has good emotional intelligence. For example, if the teacher has self awareness and problem solving skills as main cofactors in emotional intelligence, he/she will definitely be highly rated on the self-efficacy parameter (Abdolvahabi et al., 2012). Mouton et al. (2013) also stated that having high emotional intelligence rates could be related to high self-efficacy rates as well. Abdovahabi et al. (2012) proved that there is a relationship between emotional intelligence dimensions: emotional awareness, problem solving abilities, and self-efficacy. Esmaeel et al. (2013) also pointed out that there are statistical differences in work pressure between physical education 
teachers and other teachers. Thus, the physical education teacher suffers the least from work pressure. Mousavi et al. (2012) emphasized the relationship between emotional intelligence dimensions and motivation as well as occupational contentment. Babak et al. (2013) also said that emotional intelligence is not related to psychological skills, but related to management strategies. Tok \& Morali (2009) in his study pointed out the relationship between emotional intelligence and achievement for physical education teachers. The study of Yarmohammadi \& Taghibigloo (2013) focused on the physical education teachers' emotional intelligence skill which includes social skills, motivation, and empathy. Also, the results showed statistical differences between genders in their emotional intelligence skills, which took the male side. Thelwell et al. (2012), in his study, emphasized the importance of developing the emotional intelligence skills of physical trainers.

The skills of emotional intelligence for physical education teachers are very important because the students' performances are full of emotions during their classes. This requires a fully qualified emotionally intelligent and self-efficient teacher to be able to manage and control their emotions.

\section{Problem Statement}

The problem of the study occurs in an attempt to recognize the physical teachers' emotional intelligence skills and their relationship with their self-efficacy levels from the teachers' point of view. Considering the gender and the type of the school variables, the problems emerged from the following questions:

1- What are the emotional intelligence skills of the physical teachers?

2- What are the self-efficacy levels of the physical teachers?

3- Is there any relationship between emotional intelligence skills and self-efficacy levels among the physical teachers?

4- Are there any statistically significant differences of emotional intelligence skills in the perspectives of the teachers due to their gender (Male or Female)?

5- Are there any statistically significant differences of emotional intelligence skills in the perspectives of the teachers due to their school type (Public or Private)?

\section{Methodology}

The researchers used a quantitative approach to gather and analyze the study data. The study instruments were applied to a sample of physical education teachers from the Salt Directorate of Education in Jordan during the 2015/2016 year. Therefore, Table (1) shows the study sample according to gender variables. 
Table (1). Study sample according to teacher's gender

\begin{tabular}{|c|c|c|}
\hline \multicolumn{2}{|c|}{ Gender } & \multirow{2}{*}{ Total } \\
\hline Males & Females & 7 \\
\hline 2 & 5 & 57 \\
\hline 35 & 22 & 5 \\
\hline 2 & 3 & 1 \\
\hline 1 & - & 70 \\
\hline 40 & 30 & \\
\hline
\end{tabular}

\section{Study Instruments}

In attaining the study goals, the researchers have developed two scales: the emotional intelligence skills' scale and the self-efficacy levels scale. Thus, this is described as shown below.

First: Emotional Intelligence Scale: Researchers developed Schutte scale (Schutte et al., 1998) which was used in measuring the emotional intelligence skills. The researchers have translated the scale to Arabic. Thus, the scale composed of four major dimensions:

1.Optimism: It is composed of (14) items $(2,3,4,7,10,14,16,17,20,23,24,27,28,31)$.

2. Social Skills: It is composed of (8) items (5, 15, 18, 25, 29, 30, 32, 33).

3. Appraisal: It is composed of (6) items $(9,10,12,19,21,22)$.

4. Utilization: It is composed of (5) items $(11,13,26,27,30)$.

The researchers conducted validity and reliability coefficients of the emotional intelligence scale as follows:

A. Content Validity: The validity of the items was checked structurally and linguistically. Thus, it is convenience towards the dimensions in the first place, and then towards the study instrument. The researchers have shown the primary version tools to some specialists in several fields: appraisal, physical education, and educational psychology. Subsequently, the researchers took notes from the judges. Nevertheless, their agreement percentage should be $80 \%$. Some changes were made such that the final version was composed of (32) items divided into four dimensions. In addition, one item was deleted due to the judge's opinions.

B. Structural Validity: The researchers calculated the relation coefficient between the item and the dimension. Therefore, they calculated the relation coefficient between the item and the dimension while taking the deleted item under consideration. This item was less than 0.30 , which results into the deletion of two items $(7,27)$.

The corrected item's coefficients were 0.32-0.56 to the optimism dimension,

0.33-0.66 on the social skills dimension, $0.41-0.68$ on the appraisal dimension, and 
0.41- 0.68 on the utilization dimension. The corrected items along with their dimensions had $0.33-0.72$ on the optimism dimension and $0.36-66$ on the social skills. Furthermore, the appraisal dimension got $0.38-0.70$ and $0.42-$ 0.69 for the utilization dimension. The binary connective coefficients for the total score of emotional intelligence skills scale and their dimensions are shown in the table below.

Table (2). Binary correlation for the emotional intelligence skills scale and their dimensions

\begin{tabular}{|c|c|c|c|c|c|}
\hline $\begin{array}{c}\text { The connective } \\
\text { relationship }\end{array}$ & Optimism & $\begin{array}{c}\text { Social } \\
\text { skills }\end{array}$ & Appraisal & Utilization & Total \\
\hline Optimism & 1 & & & & \\
\hline Social skills & 0.53 & 1 & & & \\
\hline Appraisal & 0.45 & 0.54 & 1 & & \\
\hline Utilization & 0.55 & 0.64 & 0.67 & 1 & \\
\hline Total & 0.68 & 0.90 & 0.77 & 0.72 & 1 \\
\hline
\end{tabular}

The previous Table (2) showed that the relations between the dimensions and the emotional intelligence skills scale have varied between 0.68-0.90. Also, the relations between dimensions have been 0.45-0.67. Therefore, this implies a single dimensional scale.

C- Scale Reliability: The researchers have chosen a sample of (30) teachers who were not included in the study sample. As such, they make use of test- retest method. After two weeks of the first application of the study, the purpose of the study is used to measure the stability of the study. This is done using Person's coefficient. Also, the internal consistency is calculated using Cronbach's Alpha coefficient.

Table (3). Shows Reliability Score for Each Sub-scale emotional intelligence skills

\begin{tabular}{|c|c|c|c|}
\hline Dimensions & Test- Retest & $\begin{array}{c}\text { Internal } \\
\text { Consistency }\end{array}$ & Sum of Items \\
\hline Optimism & 0.88 & 0.82 & 12 \\
\hline Social skills & 0.93 & 0.80 & 8 \\
\hline Appraisal & 0.83 & 0.83 & 6 \\
\hline Utilization & 0.84 & 0.76 & 5 \\
\hline Total & 0.92 & 0.92 & 31 \\
\hline
\end{tabular}

Second: Self-Efficacy Scale: Schwarzer \& Jerusalem (1995) scale was used as well as the bandura (1997) scale while phrasing the items. The researchers phrased (20) items for the self-efficacy levels, and found the validity and reliability coefficient.

A. Validity: The content validity was checked by the items accuracy as well as linguistically. The researchers previewed the primary version of the self-efficacy scale to some experts in several fields such as appraisal, physical education, and educational psychology. Hence, they took notes from them considering the item adjustments. In addition, none of the (20) items of the scale were deleted. 
B. Reliability: The researchers choose a sample of (30) teachers who were not included in the study sample to perform test- retest method using the Pearson correlation. The stability of the scale was 0.85 , which is suitable for the study purposes.

\section{Results and Discussion}

The purpose of this study was to recognize the emotional intelligence skills and self-efficacy levels for the physical education teachers from both teachers and students perspective. The answers to the study questions are as follows:

First Question: What are the emotional intelligence skills of the physical teachers? The means and standard deviations of the study tools were calculated. This is done by considering the arrangement of the study instrument dissentingly according to the means as shown in Table (4).

Table (4). Means and standard deviations of emotional intelligence skills scale dimensions for the physical education teachers from the teachers' perspective

\begin{tabular}{|c|c|c|c|c|}
\hline $\begin{array}{c}\text { Dimension } \\
\text { Number }\end{array}$ & Level & Dimensions & Means & Standard Deviation \\
\hline 1 & 2 & Optimism & 3.065 & 0.91 \\
\hline 2 & 4 & Social skills & 2.277 & 0.85 \\
\hline 3 & 3 & Appraisal & 2.725 & 0.88 \\
\hline 4 & 1 & Utilization & 3.77 & 0.77 \\
\hline \multicolumn{3}{|c|}{ Total } & 2.959 & 0.852 \\
\hline
\end{tabular}

From the previous table, it is clear that emotional intelligence of the physical education teachers, as shown, depends on the fact that their degrees are within the mean. While considering the arrangement of their means for the scale dimensions, utilization came first followed by optimism. Appraisal came third, and finally was social skills.

Emotional intelligence skills for the physical education teachers from the students' perspective and their grades were above mean. Thus, the arrangement of their means on the scale sub-dimensions include: social skills was at the first place, followed by appraisal, utilization, and finally by optimism. This is shown in Table (5) below.

Table (5). Means and standard deviations of emotional intelligence scale dimensions for the physical education teachers from the students' perspective

\begin{tabular}{|c|c|c|c|c|}
\hline $\begin{array}{c}\text { Dimension } \\
\text { Number }\end{array}$ & Level & Dimensions & Means & $\begin{array}{c}\text { Standard } \\
\text { Deviation }\end{array}$ \\
\hline 1 & 4 & Optimism & 2.234 & 0.82 \\
\hline 2 & 1 & Social skills & 3.877 & 0.77 \\
\hline 3 & 2 & Appraisal & 3.725 & 0.82 \\
\hline 4 & 3 & Utilization & 2.66 & 0.67 \\
\hline \multicolumn{3}{|r}{ Total } & 3.124 & 0.77 \\
\hline
\end{tabular}


The answers to the first question showed that the answers' mean of students were higher than the teachers themselves. The students believe that their teachers have emotional intelligence. As such, social skills earned the first place. This result is compatible to the studies of Mousav et al. (2012) and Thelwell et al. (2012). Hence, this is an indication of the good relationship between the students and their teachers, as well as the activities that physical education teachers perform. This could be due to the fact that most physical activities are performed outside the classroom which gives more freedom of communication between them. According to the teachers' perspective, the utilization dimension came first which indicates that physical education teachers are well aware of the feelings of others. In addition, they have good problem solving skills. This result was compatible with the study of Yarmohammadi \& Taghibigloo (2013). The researchers explained these results as a consequence to the teachers'-students' interactions outside the classroom, as well as the teachers' understanding of the students' emotional needs more than any other teacher.

The least means were for the social skills dimension from the teachers' perspective. Hence, this was followed by optimism. The means, in general, were above expectations. As a result, this indicates that the teachers do have good emotional intelligence skills.

Second Question: What are the self-efficacy levels of the physical teachers? The means and standard deviation were calculated as shown in Table (6).

Table (6). Self-efficacy levels of physical education teachers from the teachers' perspective

\begin{tabular}{|c|c|c|c|c|c|}
\hline No & Items & Mean & $\begin{array}{c}\text { Standard } \\
\text { Deviation }\end{array}$ & Levels & Percentage \\
\hline 1 & How do I overcome obstacles? & 3.78 & 1.17 & 3 & $75.6 \%$ \\
\hline 2 & $\begin{array}{c}\text { Am I able to deal with life events } \\
\text { effectively? }\end{array}$ & 3.42 & 1.17 & 4 & $68.4 \%$ \\
\hline 3 & $\begin{array}{c}\text { Do I have good management skills while } \\
\text { dealing with emergencies? }\end{array}$ & 3.94 & 1.53 & 12 & $78.8 \%$ \\
\hline 5 & $\begin{array}{c}\text { Do I have sensible thinking when I face } \\
\text { multiple choices in life? }\end{array}$ & 3.26 & 1.20 & 8 & $65.2 \%$ \\
\hline 7 & $\begin{array}{c}\text { Do I benefit from my previous } \\
\text { experiences to overcome future } \\
\text { problems? }\end{array}$ & 3.52 & 1.29 & 7 & $70.4 \%$ \\
\hline 8 & $\begin{array}{c}\text { Am I able to focus all of my intellectual } \\
\text { abilities to achieve my goals? }\end{array}$ & 3.92 & 1.20 & 2 & $78.4 \%$ \\
\hline 9 & $\begin{array}{c}\text { Am I able to improve my abilities to be } \\
\text { stronger than I am already? } \\
\text { someone to achieve my goals when }\end{array}$ & 4.10 & 0.97 & 1 & $82 \%$ \\
\hline $\begin{array}{c}\text { Do I calmly deal with my problem } \\
\text { because I am confident about my } \\
\text { abilities? }\end{array}$ & 2.94 & 1.31 & 13 & 58.8 \\
\hline
\end{tabular}




\begin{tabular}{|c|c|c|c|c|c|}
\hline 10 & Am I able to deal with a new problem? & 2.83 & 1.27 & 15 & 56.6 \\
\hline 11 & $\begin{array}{c}\text { Do I try to identify all the aspects of a } \\
\text { problem before dealing with it? }\end{array}$ & 3.30 & 1.32 & 10 & $66 \%$ \\
\hline 12 & Am I able to organize my thoughts? & 3.35 & 1.25 & 9 & $67 \%$ \\
\hline 13 & Am I able to be a lovable person? & 3.53 & 1.14 & 5 & $70.6 \%$ \\
\hline 14 & Do I easily accomplish future plans? & 3.42 & 1.17 & 6 & $68.4 \%$ \\
\hline 15 & $\begin{array}{c}\text { Do I keep trying to achieve my goals } \\
\text { even after failing few times? }\end{array}$ & 2.96 & 1.34 & 14 & $59.2 \%$ \\
\hline 16 & Am I persistent if I failed in something? & 2.78 & 1.17 & 17 & $56 \%$ \\
\hline 17 & $\begin{array}{c}\text { Am I patient when dealing with tough } \\
\text { situations? }\end{array}$ & 2.60 & 1.53 & 20 & $52 \%$ \\
\hline 18 & Do I feel others believe in me? & 2.80 & 1.20 & 16 & $56 \%$ \\
\hline 19 & $\begin{array}{c}\text { Am I qualified to overcome future } \\
\text { problems? }\end{array}$ & 2.70 & 1.29 & 19 & $54 \%$ \\
\hline 20 & $\begin{array}{c}\text { Am I able to help others to solve their } \\
\text { problems? }\end{array}$ & 2.75 & 1.20 & 18 & $55 \%$ \\
\hline
\end{tabular}

From Table (6), we noticed that the mean answer on the self-efficacy scale varies between 2.60 - 4.10. Furthermore, it also varies with a percentage of $52 \%$ - 82\%. The item that says "Am I able to improve my abilities to be stronger than I am already?" took first place with a mean of 4.10. Thus, this is a clear indicator that physical education teachers are capable of improving their skills and become stronger to deal with future problems. The item "Am I patient when dealing with tough situations?" came last. Thus, this item indicates that physical education teachers are not patient while dealing with tough situations. From the self- efficacy scale, all the answers were above (2.75), which indicates that teachers do have selfefficacy according to their answers.

Third Question: Is there any relationship between emotional intelligence skills and self-efficacy levels among the physical teachers? Thus, the Pearson correlation coefficient was used to measure the relationship between emotional intelligence skills and self-efficacy levels for the physical education teachers. Table (7) clarifies this relationship.

Table (7). Correlation between the dimensions of emotional intelligence skills and the total score of self- efficacy levels

\begin{tabular}{|c|c|}
\hline $\begin{array}{c}\text { Dimensions of Emotional } \\
\text { Intelligence }\end{array}$ & $\begin{array}{c}\text { Total Score of Self-efficacy } \\
\text { Scale }\end{array}$ \\
\hline Optimism & 0.90 \\
\hline Social skills & 0.92 \\
\hline Appraisal & 0.89 \\
\hline Utilization & 0.87 \\
\hline
\end{tabular}

Table (7) showed that the correlation between emotional intelligence dimensions and the total degree of self- efficacy scale was high. Thus, this indicates a strong connection between emotional intelligence skills and selfefficacy levels for the physical education teachers of the Salt Directorate of 
Education. This result is confirmed by some previous studies such as the study of Abdolvahabi et al. (2012) and Mouton et al. (2013). Subsequently, their studies gave a clear indication of the compatibility between the results of the previous studies and our study results.

Fourth Question: Are there any statistically significant differences of emotional intelligence skills in the perspectives of the teachers due to their gender (Male or Female)? To answer this question, the independent sample $\mathrm{t}$ test was used as shown in Table (8).

Table (8). Differences between emotional intelligence skills according to gender

\begin{tabular}{|c|c|c|c|c|c|c|}
\hline Gender & Count & Mean & $\begin{array}{c}\text { Standard } \\
\text { Deviation }\end{array}$ & $\begin{array}{c}\text { Difference } \\
\text { between } \\
\text { means }\end{array}$ & $\begin{array}{c}\text { S } \\
\text { Value }\end{array}$ & Sig \\
\cline { 1 - 4 } Male & 40 & 3.87 & 10.7 & \multirow{2}{*}{3.2} & 3.31 & 0.02 \\
\hline
\end{tabular}

From Table (8), the mean levels of emotional intelligence were positive (3.87) for male teachers, and is higher than the female teachers' mean (3.25). Furthermore, it is also positive. The table also shows statistical differences between males and females teachers, where the $(T)$ value was 3.31. This result clarifies that the male teachers are more focused and interactive than the female teachers. In addition, this result is compatible to the study of Esmaeel et al. (2012) as well as the study of Mousav et al. (2012). Hence, this means that male teachers have higher emotional intelligence than female teachers.

Fifth Question: Are there any statistically significant differences of emotional intelligence skills in the perspectives of the teachers due to their school type (Public, Private)? To answer this question, the (T) independent sample test was used. Thus, this is seen in the Table (9) below.

Table (9). Differences between emotional intelligence skills according to school type

\begin{tabular}{|c|c|c|c|c|c|c|}
\hline $\begin{array}{c}\text { Type of } \\
\text { School }\end{array}$ & Count & Mean & $\begin{array}{c}\text { Standard } \\
\text { Deviation }\end{array}$ & $\begin{array}{c}\text { Means } \\
\text { differences }\end{array}$ & $\begin{array}{c}\text { (T) } \\
\text { value }\end{array}$ & Sig \\
\cline { 1 - 3 } Government & 55 & 3.88 & 9.72 & \multirow{2}{*}{4.7} & 5.2 & 0.00 \\
\hline Private & 15 & 3.16 & 9.40 & 4.7 & \\
\hline
\end{tabular}

From Table (9), it is clear that emotional intelligence values for the physical education teachers in the government schools was positive (3.88). Thus, this is higher than the private schools' that got 3.16. This is also positive. The table showed that there were statistical significant differences in the means of both government and private schools. Hence, this was in favor of the government schools, where $(T)$ value was (5.20). This result showed that government schools' teachers care more about the emotional skills rather than private schools' teachers. 


\section{Recommendations}

1. The study of emotional intelligence skills should be taught in both government and private universities.

2. Training programs should be developed for physical education.

3. The relationship between emotional intelligence levels and selfefficacy for the physical education teachers should be studied.

\section{Conclusion}

In conclusion, the primary aim of the current study was to investigate the relationship between emotional intelligence skills and selfefficacy levels among physical education teachers from the teachers' own perspective at Salt Directorate of Education in Jordan. Therefore, this has involved a variety of activities. We reviewed the relevant literature, asked working professionals, consulted experts, and we statistically tested the scale. In addition, we have shown above, the procedure of developing two scales: the emotional intelligence skills' scale and the self-efficacy levels scale.

Content and structural validity were evidenced in the two scales. Correlation coefficients were used to evaluate the stability of the scales. Also, it was concluded that the scales demonstrated good test-retest reliability. Piloting the scales suggests that it is easy to administer instruments and it is understandable. Therefore, they are expected to have high response rate.

\section{References:}

Abdolvahabi et al. (2012). Relationship between Emotional Intelligence and Self-efficacy in Research among Tehran Physical Education Teachers, European Journal of Experimental Biology, 2 (6), 2337-2343.

Ahadi (2009). Relationship of loneliness and self-esteem with attachment style in college student. Psychological Studies, 5(1), 95-112.

Alexandre et al. (2013). Emotional Intelligence and Self-Efficacy among Physical Education Teachers, Journal of Teaching in Physical Education, 32(1), 342-354.

Babak et al. (2013). The Relationship between Psychological Skills and Emotional Intelligence in Predicting Conflict Management Strategies of Physical Education Teachers, International Journal of Sport Studies, 3 (4), 355-360.

Bandura (1997). Self-Efficacy: The Exercise of Control, New York: W.H. Freeman.

Bandura (1999). A Social Cognitive Theory of Personality, In L. Pervin and O. John (Ed.), Handbook of personality New York: Guilford Publications. 
(Reprinted in D. Cervone and Y. Shoda [Eds.], The Coherence of Personality. New York: Guilford Press.2nd Ed., pp: 154-196.

Bar-On (2006). The Bar-On model of emotional social intelligence (ESI). Psicothema, 18, 13-25.

Brackett et al. (2011). Emotional Intelligence: Implications for Personal, Social, Academic, and Workplace Success, Social and Personality Psychology Compass, 5(1), 88-103.

Bar-On (1988). The development of a concept of psychological well-being. Unpublished doctoral dissertation, Rhodes University, South Africa.

Bar-On (1997). The EI Inventory (EQ-I): Technical manual. Toronto: MultiHealth Systems.

Cherniss \& Goleman (2006). From school to work. Social-emotional learning as the vital connection. In Elias \& Arnold (Eds.) EI and academic achievement (58-61). Thousand Oaks: Corwin Press.

Darvish et al. (2011). Examine the relationship between emotional intelligence and self-efficacy and job satisfaction of nursing education and medical city of Tabriz. Journal of Nursing and Midwifery, 21(75), 5-13.

Esmaeel et al. (2013). The Relationship Between Emotional Intelligence And Job Stress In Teacher's Of Physical Education And Non Physical Education, Advances in Environmental Biology, 7(8), 1386-1394.

Fisher \& Ashkanasy (eds.) (2000). Special issue on emotions in work life, Journal of Organizational Behavior, 21(3).

Gayathri \& Meenakshi (2013). Emotional Intelligence in the Indian Context, Global Journal of Human Social Science, 13(8), 1-8.

Freedman (2015). Enhanced Possibilities for Teaching and Learning: A Whole School Approach to Incorporating Multiple Intelligences and Differentiated Instruction, A research paper submitted in conformity with the requirements for the degree of Master of Teaching Department of Curriculum, Teaching and Learning Ontario Institute for Studies in Education of the University of Toronto.

Gayathri \& Meenakshi (2013). Emotional Intelligence in the Indian Context, Global Journal of Human Social Science, 13(8), 1-7.

Goleman (2001). Emotional intelligence: perspectives on a theory of performance. In C. Cherniss \& Goleman (eds.): The emotionally intelligent workplace. San Francisco: Jossey-Bass.

Hafezi et al. (2011). Relationship of emotional intelligence and time management with job stress in Bidboland refinery employees. New findings in psychology, 6 (19), 19-35.

Hakkak et al. (2015). Investigating the effects of emotional intelligence on social-mental factors of human resource productivity, Journal of Work and Organizational Psychology31(3), 129-134. 
Haque \& Sanaker (2013). A Comparative study of emotional intelligence between male and female $B$. ed students in west Bengal state university, International Journal of Scientific Research, 2 (12), 502-503.

Hooshmand (2007). Studying the factors influencing the effectiveness of educational organizations in Tehran Province; MA thesis, Public Administration, Islamic Azad University- Central Tehran Branch.

Hoffman (2013). Enhancing Self-Efficacy for Optimized Patient Outcomes through the Theory of Symptom Self-Management, HHS Public Access, 36(1), 16-26.

Hubble et al. (2015). Improving Negative Emotion Recognition in Young Offenders Reduces Subsequent Crime. PLoS ONE, 10(6): e0132035. doi:10.1371/journal.pone.0132035.

Iroegbu (2013). Self Efficacy and Work Performance: A Theoretical Framework of Albert Bandura's Model, Review of Findings, Implications and Directions for Future Research, Psychology and Behavioral Sciences, 4(4), 170-173.

Johnson (2008). Learning Styles and Emotional Intelligence of the Adult Leaner. Unpublished Doctoral Dissertation, Auburn University, U.S.A.

27- Kaufhold \& Johnson (2005). The Analysis of the Emotional Intelligence Skills and Potential Problem. Areas of Elementary Educators Education, 125 (4), 615-626.

Khanmohamadi (2008). Emotional intelligence: a way to excellence and performance of leadership and management. Journal of Automotive Technology, 123, 35-42.

Ladan et al. (2010). Relationship between job stress and emotional intelligence between employers of Shahid Beheshti University. Job consultation journal. Second year, 5, 9-27.

Matthews et al. (2004). Emotional intelligence: Science and myth. Cambridge, UK: MIT Press.

Moafian \& Ghanizadeh (2009). The relationship between Iranian EFL teachers 'emotional intelligence and their self-efficacy in Language Institutes. System, 37(4), 708-718.

Mousavi et al. (2012). The relationship between emotional intelligence and job satisfaction of physical education teachers, Scholars Research library, Annals of Biological Research , 3(2), 780- 78.

Mouton et al. (2013). Emotional intelligence and self-efficacy among physical education teachers. J. Teach. Phys. Educ. 32, 342-354.

Nowzari (2015). Relationship between Emotional and Decision-making Style among Mangers at Sports Organization in FARS Province, Indian Journal of Fundamental and Applied Life Sciences, 5(52), 1302-1310.

Noddings (2003). Happiness and Education. New York, NY: Cambridge University Press. 
Rahnavard (2008) Comparison of emotional intelligence between the three levels of management; Journal of Management Message, 101-118.

Pfeiffer (2001). Emotional intelligence: Popular but elusive construct. Roeper review, 23(3), 138-142.

Samuel (2007). Relationships of Emotional Intelligence and Self-Efficacy to Work Attitudes among Secondary School Teachers in Southwestern Nigeria. Journal of Medwell, 4 (1), 540-547.

Schutte et al. (1998). Development and validation of a measure of emotional intelligence. Personality and Individual Differences, 25, 167-177.

Schwarzer \& Jerusalem (1995). Generalized Self-Efficacy scale. In J. Weinman, S. Wright, \& M. Johnston, Measures in health psychology: A user's portfolio. Causal and control beliefs (pp. 35-37). Windsor, UK: NFER-NELSON.

Thelwell et al. (2008). Examining relationships between emotional intelligence and coaching efficacy, International Journal of Sport \& Exercise Psychology, 6(2), 224-235.

Tok \& Morali (2009). Trait emotional intelligence, the big five personality dimensions and academic success in physical education teacher, Social Behaviour \& Personality: An International Journal, 37(7), 921-931.

Yarmohammadi et al. (2013). Investigation Rate of Emotional Intelligence in Physical Education Teachers in Zanjan Province, International Journal of Basic Sciences \& Applied Research, 2 (1), 13-16.

Zeidner et al. (2009). What we Know about Emotional Intelligence: How It Affects Learning, Work, Relationships, and Our Mental Health, A Bradford Book. The MIT Press Cambridge, Massachusetts, London, England. 